\title{
Detection of Cryptosporidium and Cyclospora Oocysts from Environmental Water for Drinking and Recreational Activities in Sarawak, Malaysia
}

\author{
Lesley Maurice Bilung, Ahmad Syatir Tahar, ${ }^{1}$ Nur Emyliana Yunos, ${ }^{1}$ Kasing Apun, \\ Yvonne Ai-Lian Lim, ${ }^{2}$ Elexson Nillian, ${ }^{1}$ and Hashimatul Fatma Hashim ${ }^{1}$ \\ ${ }^{1}$ Faculty of Resource Science and Technology, Universiti Malaysia Sarawak, 94300 Kota Samarahan, Sarawak, Malaysia \\ ${ }^{2}$ Department of Parasitology, Faculty of Medicine, University of Malaya, 50603 Kuala Lumpur, Malaysia \\ Correspondence should be addressed to Lesley Maurice Bilung; mblesley@unimas.my
}

Received 9 August 2017; Accepted 16 October 2017; Published 6 November 2017

Academic Editor: Christen Rune Stensvold

Copyright (C) 2017 Lesley Maurice Bilung et al. This is an open access article distributed under the Creative Commons Attribution License, which permits unrestricted use, distribution, and reproduction in any medium, provided the original work is properly cited.

Cryptosporidiosis and cyclosporiasis are caused by waterborne coccidian protozoan parasites of the genera Cryptosporidium and Cyclospora, respectively. This study was conducted to detect Cryptosporidium and Cyclospora oocysts from environmental water abstracted by drinking water treatment plants and recreational activities in Sarawak, Malaysia. Water samples (12 each) were collected from Sungai Sarawak Kanan in Bau and Sungai Sarawak Kiri in Batu Kitang, respectively. In addition, 6 water samples each were collected from Ranchan Recreational Park and UNIMAS Lake at Universiti Malaysia Sarawak, Kota Samarahan, respectively. Water physicochemical parameters were also recorded. All samples were concentrated by the iron sulfate flocculation method followed by the sucrose floatation technique. Cryptosporidium and Cyclospora were detected by modified Ziehl-Neelsen technique. Correlation of the parasites distribution with water physicochemical parameters was analysed using bivariate Pearson correlation. Based on the 24 total samples of environmental water abstracted by drinking water treatment plants, all the samples $(24 / 24 ; 100 \%)$ were positive with Cryptosporidium, and only 2 samples $(2 / 24 ; 8.33 \%)$ were positive with Cyclospora. Based on the 12 total samples of water for recreational activities, 4 samples $(4 / 12 ; 33 \%)$ were positive with Cryptosporidium, while 2 samples $(2 / 12 ; 17 \%)$ were positive with Cyclospora. Cryptosporidium oocysts were negatively correlated with dissolved oxygen (DO).

\section{Introduction}

Cryptosporidium and Cyclospora are coccidian protozoan parasites that are the causative agents of waterborne outbreaks worldwide with faecal oral route as the infection transmission. Cryptosporidium is one of the leading pathogens which are responsible for majority diarrhoeal infections [1]. There are two most common species infecting human, namely, Cryptosporidium hominis and Cryptosporidium parvum. Infectious dose of the parasite varies upon human immune status. A study on human volunteers revealed that the median infectious dose of $C$. parvum $\left(\mathrm{ID}_{50}\right)$ infection is 132 oocysts for healthy individuals and as low as 30 oocysts can initiate an infection [2]. A person without previous exposure to cryptosporidiosis is more susceptible to low dose of oocyst as no anti-C. parvum-specific immunoglobulins is found in the body [3].

Cryptosporidium oocyst has become a concern for the water industry as it is infectious, robust in the environment, and resistant to disinfectants (chlorine and chloramines) and can compromise filter bed of the water filtration system $[4,5]$. In other developed countries such as the United States and Canada, Cryptosporidium represents one of the key parameters for determining the safety of environmental water as drinking water supply $[6,7]$ and was classified under Category 1 in Unitary Environmental Classification of Waterand Excreta-Related Disease.

Cyclospora cayetanensis can also cause prolonged diarrhoea, nausea, and abdominal cramps, and human is the only natural host of the parasite [4]. The parasite is resistant to 
chlorination like Cryptosporidium. Medications usually given to treat enteric diseases such as albendazole, azithromycin, norfloxacin, tinidazole, quinacrine, nalidixic acid, and diloxanide furoate are not effective against Cyclospora [8]. Infectious dose of Cyclospora is unknown but suggested to be as low as 10-100 oocysts [9].

Survivability of Cryptosporidium in drinking water has drawn substantial concern by the water and health agencies. To the best of our knowledge, only two published studies about Cryptosporidium contamination on raw water for water treatment plants have been conducted in Malaysia. These have revealed occurrence of Cryptosporidium to be within $0-0.06$ oocyst/L $[10,11]$. Although there is no outbreak of cryptosporidiosis up to the present time in the country, many sporadic cases have been reported in immunocompromised individuals [12-17] and animals [18-23]. These do not count the undiagnosed and asymptomatic individuals, self-limiting cases, and unpublished data. In other Asian countries, the parasite has been encountered in tap water as little as one oocyst from 115 samples [24]. In Northern Thailand, 14.42\% of natural river water samples $(15 / 104)$ were contaminated with the parasite [25], while a study on untreated and treated water from 20 frozen food factories in Thailand found 35\% untreated water samples $(7 / 20)$ were positive with the parasite but $0 \%$ in treated water samples $(0 / 20)$ [26].

Sungai Sarawak Kanan, Bau and Sungai Sarawak Kiri, and Batu Kitang are rivers contributing to important water basins. The raw waters are abstracted by the nearby water treatment plants to supply treated water to the areas of Bau and Kuching [27]. Ranchan Recreational Park is $60 \mathrm{~km}$ away from Kuching which is located at the south of Serian. It gains much attraction from the locals especially during weekend. UNIMAS Lake is a man-made lake located at the west wing of the main campus of Universiti Malaysia Sarawak and is popular among students for kayaking activity. Previously, Richard et al. [11] conducted a study on parasite contamination on Sungai Sarawak Kiri. However, the present study will also include Sungai Sarawak Kanan as sources of river water abstracted by drinking water treatment plants. This study is the first to determine the contamination of Cryptosporidium and Cyclospora in Sarawak recreational areas. The finding of this study provides preliminary data to illustrate parasite occurrences in the study areas.

\section{Materials and Methods}

2.1. Sampling Sites and Collection. A total of 24 raw water samples for drinking were collected from Sungai Sarawak Kanan in Bau $(n=12)$ and Sungai Sarawak Kiri in Batu Kitang $(n=12)$, while a total of 12 water samples for recreational activities were collected from Ranchan Recreational Park $(n=6)$ and UNIMAS Lake $(n=6)$. The samples of raw water for drinking were collected separately at surface and subsurface (approximately 5 meters depth) at each station (upstream, midstream, and downstream) from Sungai Sarawak Kanan and Sungai Sarawak Kiri. The water was collected by pumping into sterile polypropylene containers with the aid of a vacuum pump (Rhos Motor) using $12 \mathrm{~V}$ energy source from a car battery. The distance between each sampling station was approximately between 500 and 2000 meters due to poor accessibility. The water samples for recreational activities were collected at the surface by using the similar equipment. The distance between each sampling station was approximately 100 meters. The samples of both for drinking and recreational were collected once in two weeks constitutively, starting from January 2017 to March 2017.

2.2. Measurements of Physicochemical Parameters. The physicochemical parameters analysed in this study were temperature, $\mathrm{pH}$ (Walklab $\mathrm{pH}$ meter, TI9000), conductivity, Total Dissolved Solid (Cyberscan meter, CON II), turbidity (Martini, Mi 415), and dissolved oxygen (Professional Series oxygen meter, YSI Pro 20). All the physicochemical parameters were measured in the lab except for temperature and $\mathrm{pH}$. The data were recorded.

2.3. Flocculation and Sedimentation. This method was in accordance with the procedure by Karanis and Kimura [28] with little modification. Firstly, $20 \mathrm{ml}$ of ferric sulfate $(0.2525 \mathrm{M})$ solution was added to 101 of the water samples and the $\mathrm{pH}$ was adjusted to $6.0 \pm 0.05$. Flocs would form and were let to settle overnight (approximately $14 \mathrm{~h}$ ) at room temperature. Afterwards, the clear fluid was cautiously discarded without disturbing the sediment. The sediments were centrifuged at $2,100 \times \mathrm{g}$ for $10 \mathrm{~min}\left(4^{\circ} \mathrm{C}\right.$, no brake $)$ and supernatant was discarded until leaving approximately $1 \mathrm{ml}$ of pellet and added with $1 \mathrm{ml}$ of lysis buffer ( $0.3997 \mathrm{M}$ citric acid monohydrate, $0.5998 \mathrm{M}$ trisodium citrate dihydrate, $\mathrm{pH} 4.7$ ). The pellets were incubated at room temperature for $1 \mathrm{~h}$ (with intermittent vortexing every $15 \mathrm{~min}$ ). Subsequently, the lysis buffer was washed off by centrifugation at 2,100 $\times \mathrm{g}$ for $10 \mathrm{~min}$ $\left(4^{\circ} \mathrm{C}\right)$ with distilled water up to $50 \mathrm{ml}$. The washing step was performed twice.

2.4. Sucrose Flotation. This procedure was in accordance with the procedure by Kuczynska \& Shelton [29] with a little modification with the increment of specific gravity. The pellets were underlaid with sucrose solution (3.7362 M, 1.27 specific gravity) and centrifuged at $300 \times \mathrm{g}$ for 5 minutes. A coverslip was gently placed on the top of the negative meniscus of the samples and let to stand for 30 minutes. The samples attached on the coverslip surface were scrapped into microcentrifuge tubes and washed thrice at $1000 \times \mathrm{g}$ for 10 minutes. The final pellets were concentrated to $50 \mu \mathrm{l}$ volume with distilled water.

2.5. Detection of Cryptosporidium and Cyclospora Oocyst. A volume of $50 \mu \mathrm{l}$ of the samples was stained with modified Ziehl-Neelsen technique, according to Casemore et al. [30]. The samples were observed under a microscope at 1000x magnification and measured by using $\mathrm{Cell}^{\wedge} \mathrm{D}$ software (Olympus). Cryptosporidium oocysts appeared as pinkish red, almost spherical and measured 4-6 $\mu \mathrm{m}$ [31]. Cyclospora oocysts appeared light clear pink to deep red, containing granules or bubbly appearance, and measured 8-10 $\mu \mathrm{m}$ [32]. The samples were observed twice to prevent errors. The results were compared with the image gallery by Centers for Disease Control and Prevention [33]. 
TABLE 1: Concentration of Cryptosporidium and Cyclospora oocysts from water samples abstracted by drinking water treatment plants.

\begin{tabular}{|c|c|c|c|c|c|}
\hline \multirow{2}{*}{ Water sample } & \multirow{2}{*}{ Date } & \multirow{2}{*}{ Station } & \multirow{2}{*}{ Water column } & \multicolumn{2}{|c|}{ Oocyst $/ \mathrm{L}^{\mathrm{a}}$} \\
\hline & & & & Cryptosporidium & Cyclospora \\
\hline \multirow{12}{*}{ Sungai Sarawak Kiri } & \multirow{6}{*}{$25-01-17$} & \multirow{2}{*}{ Downstream } & Surface & 0.9 & 0.2 \\
\hline & & & Subsurface & 1.1 & 0.1 \\
\hline & & \multirow{2}{*}{ Midstream } & Surface & 0.3 & ND \\
\hline & & & Subsurface & 0.2 & ND \\
\hline & & \multirow{2}{*}{ Upstream } & Surface & 0.2 & ND \\
\hline & & & Subsurface & ND & ND \\
\hline & \multirow{6}{*}{ 08-02-17 } & \multirow{2}{*}{ Downstream } & Surface & 1.0 & ND \\
\hline & & & Subsurface & 2.7 & ND \\
\hline & & \multirow{2}{*}{ Midstream } & Surface & 0.4 & ND \\
\hline & & & Subsurface & 0.7 & ND \\
\hline & & \multirow{2}{*}{ Upstream } & Surface & 0.3 & ND \\
\hline & & & Subsurface & ND & ND \\
\hline Total positive sample & & & & $10 / 12(83.33 \%)$ & $2 / 12(16.67 \%)$ \\
\hline \multirow{12}{*}{ Sungai Sarawak Kanan } & \multirow{6}{*}{$01-02-17$} & \multirow{2}{*}{ Downstream } & Surface & ND & ND \\
\hline & & & Subsurface & ND & ND \\
\hline & & \multirow{2}{*}{ Midstream } & Surface & 0.3 & ND \\
\hline & & & Subsurface & ND & ND \\
\hline & & \multirow{2}{*}{ Upstream } & Surface & 0.5 & ND \\
\hline & & & Subsurface & ND & ND \\
\hline & \multirow{6}{*}{$27-02-17$} & \multirow{2}{*}{ Downstream } & Surface & ND & ND \\
\hline & & & Subsurface & $\mathrm{ND}$ & ND \\
\hline & & \multirow{2}{*}{ Midstream } & Surface & ND & ND \\
\hline & & & Subsurface & 0.1 & ND \\
\hline & & \multirow{2}{*}{ Upstream } & Surface & 0.8 & ND \\
\hline & & & Subsurface & ND & ND \\
\hline Total positive sample & & & & $4 / 12(33.33 \%)$ & $0 / 12(0.00 \%)$ \\
\hline
\end{tabular}

${ }^{a}$ Oocyst/L denotes that the number of the oocysts is expressed per litre of water sample; ND denotes not determined.

2.6. Statistical Analysis. The concentration of Cryptosporidium and Cyclospora oocysts were expressed per litre by dividing the number of positive respective parasites with ten litres. Correlation between the parasites occurrence and physicochemical parameters was analysed by using bivariate Pearson correlation analysis. The data were analysed using SPSS software version 24.0 (IBM, New York). The distribution of the oocyst based on streams and water column was expressed in mean.

\section{Results}

Overall, there were a total of 36 environmental water samples collected, comprised of 24 river water samples used for drinking and 12 river and lake water samples used for recreational activities. As displayed in Tables 1 and 4, 77.8\% $(n=28 / 36)$ of these water samples were positive for Cryptosporidium oocysts, whereas $11.1 \%(n=4 / 36)$ were found to be contaminated with Cyclospora.

3.1. Occurrence of Cryptosporidium and Cyclospora in Environmental Water Samples Abstracted by Drinking Water Treatment Plants. Of the 24 environmental water samples (i.e., river) abstracted by drinking water treatment plants, $58.3 \%$ (14/24) were positive with Cryptosporidium oocysts. Higher concentrations were detected in water samples from Sungai Sarawak Kiri compared to Sungai Sarawak Kanan. Only $8.33 \%(2 / 24)$ were positive with Cyclospora. These positive samples were from Sungai Sarawak Kiri. All the samples from Sungai Sarawak Kanan were negative (Table 1).

In addition, distribution of Cryptosporidium and Cyclospora oocysts was also analysed based on the sampling site of the river system (i.e., upstream, midstream and downstream) and water column (i.e., surface and subsurface). As shown in Table 2, the highest number of Cryptosporidium and Cyclospora was found at the downstream sampling sites. Refer to Figure 1 for the representatives of Cryptosporidium and Cyclospora oocysts detected.

Higher concentrations of Cryptosporidium oocyst were detected from the subsurface compared to the surface. In contrast, concentrations of Cyclospora oocyst were higher in water samples from the surface compared to the subsurface (Table 3).

3.2. Occurrence of Cryptosporidium and Cyclospora in Environmental Water Samples Used for Recreational Activities. 


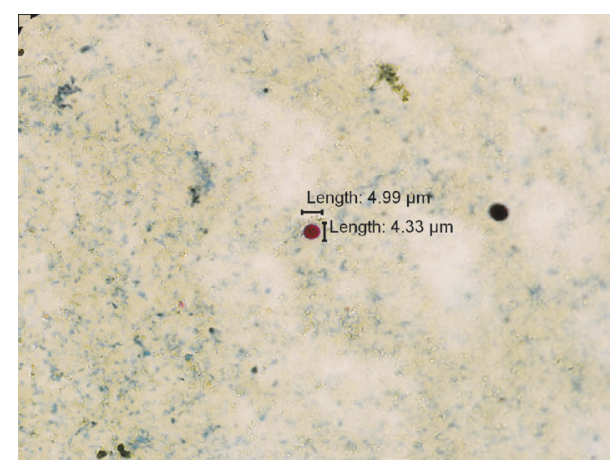

(a)

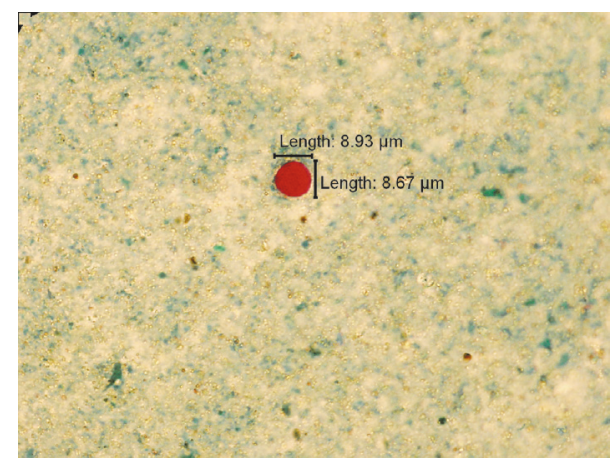

(c)

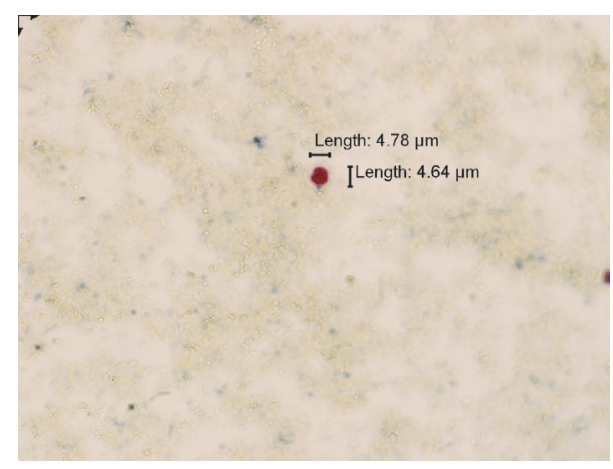

(b)

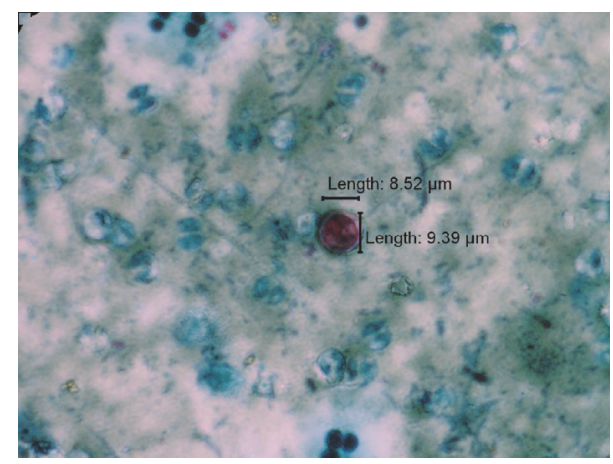

(d)

FIGURE 1: ((a) and (b)) Cryptosporidium oocyst detected in subsurface water samples from Sungai Sarawak Kiri, (c) Cyclospora oocyst detected in a surface water sample from Sungai Sarawak Kiri, and (d) Cyclospora oocyst detected in a water sample from UNIMAS Lake.

TABLE 2: Mean concentration of Cryptosporidium and Cyclospora oocysts according to sampling sites of the river system.

\begin{tabular}{lcc}
\hline River stream & $\begin{array}{c}\text { Cryptosporidium } \\
\text { Oocyst/L } \\
(\text { mean } \pm \text { SD) }\end{array}$ & $\begin{array}{c}\text { Cyclospora } \\
\text { Oocyst/L } \\
(\text { mean } \pm \text { SD) }\end{array}$ \\
\hline Upstream & $0.22 \pm 0.29$ & $0.0 \pm 0.0$ \\
Midstream & $N=4$ & $N=4$ \\
Downstream & 0.23 & $0.0 \pm 0.0$ \\
& $N=4$ & $N=4$ \\
\hline
\end{tabular}

$N$ signifies total number of the samples.

Out of the total 12 samples collected from UNIMAS Lake and Ranchan Recreational Park, 33.3\% (4/12) were positive with Cryptosporidium. All the positive samples were isolated from UNIMAS Lake. No Cryptosporidium was found in the samples from Ranchan Recreational Park. As for Cyclospora, $16.7 \%(2 / 12)$ were positive in water samples from UNIMAS Lake. No Cyclospora was detected in the samples from Ranchan Recreational Lake (Table 4).

3.3. Correlation of the Parasite Oocyst Occurrence with Physicochemical Parameters. Based on Table 5, distribution of Cryptosporidium oocysts had no correlation with all the
TABLE 3: Mean concentration of Cryptosporidium and Cyclospora oocysts according to surface and subsurface river level.

\begin{tabular}{lcc}
\hline Water column & $\begin{array}{c}\text { Cryptosporidium } \\
\text { Oocyst/L } \\
(\text { mean } \pm \mathrm{SD})\end{array}$ & $\begin{array}{c}\text { Cyclospora } \\
\text { Oocyst/L } \\
(\text { mean } \pm \mathrm{SD})\end{array}$ \\
\hline Surface & $0.391 \pm 0.347$ & $\mathbf{0 . 0 1 6} \pm \mathbf{0 . 0 5 7}$ \\
& $N=12$ & $\mathbf{N}=\mathbf{1 2}$ \\
Subsurface & $\mathbf{0 . 4} \pm \mathbf{0 . 8 0 4}$ & $0.008 \pm 0.028$ \\
& $\mathbf{N}=\mathbf{1 2}$ & $N=12$ \\
\hline$N$ signifies the total number of samples. &
\end{tabular}

physicochemical parameters except DO with negative correlation. Correlation of Cyclospora and the physicochemical parameters was not analysed in this study due to the small number of positive samples.

\section{Discussion}

Cryptosporidium $(18 / 36 ; 50 \%)$ were detected more than Cyclospora $(4 / 36 ; 11.11 \%)$ from both types of water used for drinking and recreational activities. In comparison, Cryptosporidium is of greater public health concerns as it has been the causative agent for numerous waterborne outbreaks due to its small size $(4-6 \mu \mathrm{m})$ and being infectious after being shed from the infected hosts. Cyclospora is usually shed in low 
TABLE 4: Concentration of Cryptosporidium and Cyclospora oocysts from water samples for recreational activities.

\begin{tabular}{|c|c|c|c|c|}
\hline \multirow{2}{*}{ Water sample } & \multirow{2}{*}{ Date } & \multirow{2}{*}{ Station } & \multicolumn{2}{|c|}{ Oocyst $/ \mathrm{L}^{\mathrm{a}}$} \\
\hline & & & Cryptosporidium & Cyclospora \\
\hline \multirow{6}{*}{ UNIMAS Lake (West Campus) } & \multirow{3}{*}{$15-02-17$} & Outlet & ND & ND \\
\hline & & Inlet & 0.2 & ND \\
\hline & & Inlet & 0.7 & ND \\
\hline & \multirow{3}{*}{$13-03-17$} & Outlet & ND & ND \\
\hline & & Inlet & 1.2 & 0.2 \\
\hline & & Inlet & 0.7 & 0.6 \\
\hline Total positive sample & & & $4 / 6(66.67 \%)$ & $2 / 6(33.33 \%)$ \\
\hline \multirow{6}{*}{ Ranchan Recreational Park } & \multirow{3}{*}{$15-02-17$} & Downstream & ND & ND \\
\hline & & Midstream & ND & ND \\
\hline & & Upstream & ND & ND \\
\hline & \multirow{3}{*}{$13-03-17$} & Downstream & ND & ND \\
\hline & & Midstream & ND & ND \\
\hline & & Upstream & ND & ND \\
\hline Total positive sample & & & $0 / 6(0.00 \%)$ & $0 / 6(0.00 \%)$ \\
\hline
\end{tabular}

${ }^{a}$ Oocyst/L denotes that the number of the oocysts is expressed per litre of water sample; ND denotes not determined.

TABLE 5: Pearson correlation $r$ and $p$ values for Cryptosporidium and Cyclospora tested for bivariate correlation with temperature, $\mathrm{pH}$, turbidity, dissolved oxygen, conductivity, and Total Dissolved Solid.

\begin{tabular}{|c|c|c|c|c|c|c|}
\hline \multirow[b]{2}{*}{ Parasite } & \multicolumn{6}{|c|}{ Correlation of oocyst with physicochemical parameters } \\
\hline & Temperature & $\mathrm{pH}$ & Turbidity & Dissolved oxygen & Conductivity & $\begin{array}{c}\text { Total } \\
\text { Dissolved } \\
\text { Solid }\end{array}$ \\
\hline Cryptosporidium & $\begin{array}{l}r=0.321 \\
p=0.056\end{array}$ & $\begin{array}{c}r=-0.124 \\
p=0.470\end{array}$ & $\begin{array}{l}r=0.042 \\
p=0.808\end{array}$ & $\begin{array}{c}r=-0.434^{* *} \\
p=0.008\end{array}$ & $\begin{array}{l}r=0.123 \\
p=0.476\end{array}$ & $\begin{array}{l}r=0.238 \\
p=0.162\end{array}$ \\
\hline Cyclospora & $\begin{array}{c}r=0.517^{* *} \\
p=0.001\end{array}$ & $\begin{array}{l}r=0.010 \\
p=0.954\end{array}$ & $\begin{array}{l}r=0.013 \\
p=0.941\end{array}$ & $\begin{array}{c}r=-0.395^{*} \\
p=0.017\end{array}$ & $\begin{array}{l}r=0.065 \\
p=0.708\end{array}$ & $\begin{array}{l}r=0.152 \\
p=0.375\end{array}$ \\
\hline
\end{tabular}

$r$ value signifies correlation coefficient value; $p$ value signifies probability value. ${ }^{* *}$ Correlation is significant at the 0.01 level (2-tailed). ${ }^{*}$ Correlation is significant at the 0.05 level (2-tailed).

numbers even by immunocompromised hosts. Outbreaks of cryptosporidiosis have no seasonality compared to cyclosporiasis. As this pattern, Cryptosporidium can cause higher number of infections than Cyclospora. These might be the reasons of Cyclospora being scarce in the water samples [34].

4.1. Occurrence of Cryptosporidium and Cyclospora in Environmental Water Samples Abstracted by Drinking Water Treatment Plants. There were a higher number of positive samples with Cryptosporidium (14/24) than Cyclospora (2/24) from Sungai Sarawak Kanan and Sungai Sarawak Kiri. Cryptosporidium were detected in the range of 0.1-2.7 oocysts/L, while Cyclospora were detected in the range of 0.1-0.2 oocysts/L. Both rivers contribute to the raw water supply to Bau Water Treatment Plant and Batu Kitang Water Treatment Plant. Both parasites have monoxenous development, low dose of oocysts, and resistant to most disinfectants [35, 36], but Cryptosporidium is more hazardous because of being readily infectious after shed [37]. The occurrence of these waterborne parasites is of public health concern for the water treatment industries. High occurrence of these parasites in natural water can lead to an outbreak, whereas low numbers of oocysts may not be detected during surveillance.
The present study obtained higher concentrations of Cryptosporidium (0.1-2.7 oocysts/L) compared to the study by Richard et al. [11] (0.02-0.04 oocysts/L) from raw water of Sungai Sarawak Kiri. This might be due to the different concentration methods used. The current study applied flocculation which in some reported recorded better recovery rates compared to membrane filtration method [38-40].

The water treatment industries in Malaysia rely on conventional treatment processes which include coagulation, flocculation, sedimentation, filtration, disinfection, and $\mathrm{pH}$ adjustment. Alum-lime and chloramination are used during coagulation and disinfection, respectively [27]. According to a report, nearly all water treatment plants practising this system are at risk of passing Cryptosporidium into public treated water at the rate of 52 infections per 10,000 people per year [41]. The worst outbreak ever recorded took place in Milwaukee in 1993. The principal causes were attributed to poor quality of natural water supply and faulty flocculation and filtration processes. These vents subsequently led to increase of turbidity and Cryptosporidium in the treated water [42].

Cryptosporidium is one of the most resistant and recalcitrant pathogens in water. Its oocyst can withstand high concentration chlorine treatment for 18 hours and 
chloramines. Advanced studies have revealed that chlorine oxide, ozone, and ultraviolet (UV) can inactivate Cryptosporidium, but several advantages such as scale-up issues and turbidity interference impede extrapolation in the real circumstances [43]. Suboptimal flocculation and filtration allow the oocysts to survive into the drinking water supply [44]. Size of Cryptosporidium which is one-third of an amoeba or Giardia can compromise the filtration barrier [5]. Installation of high throughput filtration system such as bank filtration and membrane filtration is capable of filtering out Cryptosporidium from the treated water [41] but these technologies are costly.

Cryptosporidiosis is more severe to acquired or congenital immunocompromised individuals such as children particularly below 5 years old, elders, and people with chronic illnesses like Human Immunodeficiency Virus (HIV) infection [12-17, 45]. Public awareness about the practice of boiling water is crucial to prevent further infection in households. Cryptosporidium can be inactivated by boiling at $72.4^{\circ} \mathrm{C}$ or higher or at $64.2^{\circ} \mathrm{C}$ at least for 2 minutes [46]. Alternatively, water purifiers with $1 \mu \mathrm{m}$ filter can be used $[47,48]$. The infection is riskier to animals through contaminated drinking water. The most common species is Cryptosporidium parvum that infects neonatal calves particularly aged $1-3$ weeks [49].

The present results showed that Cryptosporidium oocysts were the highest in water samples from the downstream $(0.71 \pm 0.94$ oocysts/L) of the rivers. This is followed by the midstream $(0.25 \pm 0.23$ oocysts/L) and the upstream $(0.22 \pm 0.29$ oocysts/L). Cyclospora were only present from the downstream, but the quantity was very low $(0.03 \pm$ 0.07 oocysts/L). The downstream areas receive water from upstream and midstream. Any contaminations from the two areas can contaminate downstream as well. Besides, this study suggests that contaminations of Cryptosporidium and Cyclospora in the areas most probably originated from the housing areas, animal farms, waste disposal, and swimming activities along the river.

Both Sungai Sarawak Kanan and Sungai Sarawak Kiri have settlement areas at the downstream sampling site. Contamination from the lands can be brought to the rivers by drainage or water runoff during raining. Animal farms were seen adjacent to midstream area. C. parvum is the most encountered species infecting cattle besides $C$. muris with lower incidence reported in prevalence studies. It has been reported that infected cattle sheds high load and frequency of the parasite oocyst in faeces. High contamination can happen from the farms when no barriers or buffer zones such as vegetation areas are set up or if herds are not thwarted from roaming near to the stream [50]. Another possible factor of contamination could be by the unhygienic waste disposal such as nappies which were observed in Sungai Sarawak Kiri. Some bathers were also seen swimming during the sampling days. It must be noted that any person experiencing diarrhoea should avoid getting in contact with water to prevent contamination with Cryptosporidium [51].

No distinct difference was noted in the distribution of Cryptosporidium from surface $(0.391 \pm 0.347$ oocysts/L) and subsurface $(0.4 \pm 0.804$ oocysts/L) water column. A study has highlighted that oocyst resuspension can occur at surface and subsurface of the water column influenced by various factors such as rainfall intensity, river flow [52], water usage, human activities, and effluent discharge flowrate. Specific gravity of Cryptosporidium is 1.080 s.p. [53] and $1.05-1.31 \mu \mathrm{m} / \mathrm{s}$ of settling velocity [54]. Although information on depth of Sungai Sarawak Kanan and Sungai Sarawak Kiri is not available, available information stated that the duration of days taken by parasite oocyst to settle to 5 -meter subsurface is approximately 55 days 2 hours- 44 days 4 hours and the settling rate would increase if oocysts are attached to particulate matters and subjected to the velocity of the matters $[25,55]$.

Higher concentrations of Cyclospora were found from surface water samples $(0.016 \pm 0.057$ oocysts/L) than subsurface $(0.008 \pm 0.028$ oocysts/L) of the water column. This pattern could suggest that the introduction of this parasite into the water has recently occurred and the oocysts float freely with the water flow. Although information of its settling velocity is not available, it can be postulated that the settling velocity would probably be faster than Cryptosporidium due to its bigger size.

4.2. Occurrence of Cryptosporidium and Cyclospora in Environmental Water Samples Used for Recreational Activities. A higher number of samples were positive with Cryptosporidium (4/12) than Cyclospora (2/12) from UNIMAS Lake and Ranchan Recreational Park. Cryptosporidium were detected in the range of $0.2-1.2$ oocysts/L, while Cyclospora were detected in the range of $0.2-0.6$ oocysts/L. This study did not detect Cryptosporidium and Cyclospora at all the 6 samples from Ranchan Recreational Park. The fast streamflow might have swept away parasites in the water lead to underreporting especially if the oocysts were present in low numbers. Sunderland et al. [56] pointed out that there was a strong correlation with the number of bathers and presence of Cryptosporidium. The public health concern still exists in Ranchan as its waterfall receives many visitors especially during weekends and holidays where contamination from swimmers can happen as mentioned.

In UNIMAS Lake, only Cryptosporidium oocysts were detected which were all from inlet areas that receive drainage water from hostels and restaurants. However, information on the status of water quality of the drainage water from the hostels and restaurants is not available. However, the risk of contracting cryptosporidiosis is still low because the students mainly do kayaking during curricular activities. High risk can happen through oral transmission such as accidental swallowing of the water when the students fall into the water.

To reduce water contamination by swimming activities, the public should (i) reduce the number of bathers; (ii) restrict children with diapers from being near to water; and (iii) impede bathers with gastrointestinal diseases from swimming; (iv) bathers should use shower before swimming; (v) swimming areas should be far from sources of contaminations [57].

4.3. Correlation of Cryptosporidium and Cyclospora with Physicochemical Parameters. Physicochemical parameters are preliminary indicator of water quality to indicate oocysts 
distribution. Among the 6 physicochemical parameters, Cryptosporidium was negatively correlated with DO $(p<0.01)$. Based on the previous studies, it is noteworthy that Cryptosporidium had association with turbidity [58-60]. High turbidity can indicate containing higher concentration of pathogen in the water [9], high runoff intensity, and effluent discharge. This study could not analyse the correlation between Cyclospora and the physicochemical parameters because the number of positive samples were too small.

The limitation faced in this study was the small sample size that could be less significant to represent the whole population. We recommend further study to involve more samples, frequent sampling, and variety of station locations. Besides, species distribution of both parasites should be studied to predict the actual risk of infection by humanpathogenic genotypes via molecular techniques.

\section{Conclusion}

The findings of this study revealed that higher concentrations of Cryptosporidium than Cyclospora were found in water used for abstraction of drinking water treatment plant and recreational activities in Sarawak, Malaysia.

\section{Conflicts of Interest}

The authors declare no conflicts of interest.

\section{Authors' Contributions}

Lesley Maurice Bilung and Yvonne Ai-Lian Lim contributed to the design of the study. Ahmad Syatir Tahar and Nur Emyliana Yunos conducted the experiment and data analyses. Ahmad Syatir Tahar and Lesley Maurice Bilung wrote the manuscript. Kasing Apun, Hashimatul Fatma Hashim, and Elexson Nillian were involved in the manuscript editing. Yvonne Ai-Lian Lim provided opinions for the manuscript. All authors read and approved the final manuscript.

\section{Acknowledgments}

Appreciation goes to Tun Openg Chair Grant F07(ORC)/ $1223 / 2015 /(04)$. The authors also would like to acknowledge the Department of Chemistry, Universiti Malaysia Sarawak, for granting permission to use the equipment for water quality analyses.

\section{References}

[1] K. L. Kotloff, J. P. Nataro, W. C. Blackwelder et al., "Burden and aetiology of diarrhoeal disease in infants and young children in developing countries (the Global Enteric Multicenter Study, GEMS): a prospective, case-control study," The Lancet, vol. 382, no. 9888, pp. 209-222, 2013.

[2] H. L. DuPont, C. L. Chappell, C. R. Sterling, P. C. Okhuysen, J. B. Rose, and W. Jakubowski, "The infectivity of Cryptosporidium parvum in healthy volunteers," The New England Journal of Medicine, vol. 332, no. 13, pp. 855-859, 1995.

[3] P. C. Okhuysen, C. L. Chappell, J. H. Crabb, C. R. Sterling, and H. L. DuPont, "Virulence of three distinct Cryptosporidium parvum isolates for healthy adults," The Journal of Infectious Diseases, vol. 180, no. 4, pp. 1275-1281, 1999.

[4] M. Kitajima, E. Haramoto, B. C. Iker, and C. P. Gerba, “Occurrence of Cryptosporidium, Giardia, and Cyclospora in influent and effluent water at wastewater treatment plants in Arizona," Science of the Total Environment, vol. 484, no. 1, pp. 129-136, 2014.

[5] R. A. Dillingham, A. A. Lima, and R. L. Guerrant, "Cryptosporidiosis: Epidemiology and impact," Microbes and Infection, vol. 4, no. 10, pp. 1059-1066, 2002.

[6] Health Canada, Enteric Protozoa: Giardia and Cryptosporidium. Retrieved on 22 May 2017 from https://www.hc-sc.gc.ca/ ewh-semt/pubs/water-eau/protozoa/index-eng.php.

[7] United States Environmental Protection Agency, Long Term 2 Enhanced Surface Water Treatment Rule Documents. Retrieved on 22 May 2017 from https://www.epa.gov/dwreginfo/longterm-2-enhanced-surface-water-treatment-rule-documents.

[8] C. A. Warren, "Cyclosporiasis: An Update," in Current Infectious Disease Reports, vol. 11, pp. 502-513, 2009.

[9] E. N. Ali, S. A. Muyibi, H. M. Salleh, M. Z. Alam, and M. R. M. Salleh, "Production of natural coagulant from Moringa oleifera seed for application in treatment of low turbidity water," Journal of Water Resource and Protection, vol. 2, p. 259, 2010.

[10] R. A. Ahmad, E. Lee, I. T. L. Tan, and A. G. Mohamad-Kamel, "Occurrence of Giardia cysts and Cryptosporidium oocysts in raw and treated water from two water treatment plants in Selangor, Malaysia," Water Research, vol. 31, no. 12, pp. 31323136, 1997.

[11] R. L. Richard, I. Ithoi, M. A. A. Majid et al., "Monitoring of waterborne parasites in two drinking water treatment plants: A study in Sarawak, Malaysia," International Journal of Environmental Research and Public Health, vol. 13, no. 7, article no. 641, 2016.

[12] A. Iqbal, Y. A. L. Lim, J. Surin, and B. L. H. Sim, "High diversity of Cryptosporidium subgenotypes identified in Malaysian HIV/AIDS individuals targeting gp60 gene," PLoS ONE, vol. 7, no. 2, Article ID e31139, 2012.

[13] I. Asma, S. Johari, L. Benedict, L. H. Sim, and Y. A. L. Lim, "How common is intestinal parasitidm in HIV-infected patients in Malaysia?” Tropical Biomedicine, vol. 28, pp. 400-410, 2011.

[14] Y. A. Lim, A. Iqbal, J. Surin et al., "First genetic classification of Cryptosporidium and Giardiafrom HIV/AIDS patients in Malaysia," Infection, Genetics and Evolution, vol. 11, pp. 968-974, 2011.

[15] A. R. Zaidah, Y. Y. Chan, H. Siti Asma et al., "Detection of Cryptosporidium parvum in HIV-infected patients in malaysia using a molecular approach," Southeast Asian Journal of Tropical Medicine and Public Health, vol. 39, no. 3, pp. 511-516, 2008.

[16] B. S. Menon, M. D. Shukri Abdullah, F. Mahamud et al., "Low prevalence of Cryptosporidium parvum in hospitalized children in Kota Bharu, Malaysia," Southeast Asian Journal of Tropical Medicine and Public Health, vol. 32, no. 2, pp. 319-322, 2001.

[17] A. M. Kamell, S. Nurahan Maning, S. Murad, A. Nasuruddin, and K. P. F. Lail, "Cryptosporidiosis among HIV positive intravenous drug users in," Malaysia, vol. 25, pp. 650-653, 1994.

[18] A. Muhid, I. Robertson, J. Ng, and U. Ryan, "Prevalence of and management factors contributing to Cryptosporidium sp. infection in pre-weaned and post-weaned calves in Johor, Malaysia," Experimental Parasitology emphasizes, vol. 127, no. 2, pp. 534-538, 2011. 
[19] J. X. Quah, S. Ambu, Y. A. Lim, M. A. Mahdy, and J. W. Mak, "Molecular identification of Cryptosporidium parvum from avian hosts.," Parasitology, vol. 138, no. 5, pp. 573-577, 2011.

[20] N. A. Halim, J. Plutzer, M. A. Bakheit, and P. Karanis, "First report of Cryptosporidium deer-like genotype in Malaysian cattle," Veterinary Parasitology, vol. 152, no. 3-4, pp. 325-329, 2008.

[21] Y. A. L. Lim, R. Ngui, J. Shukri, M. Rohela, and H. R. Mat Naim, "Intestinal parasites in various animals at a zoo in Malaysia," Veterinary Parasitology, vol. 157, no. 1-2, pp. 154-159, 2008.

[22] Y. A. L. Lim, M. Rohela, and M. M. Shukri, "Cryptosporidiosis among birds and bird handlers at Zoo Negara, Malaysia," Southeast Asian Journal of Tropical Medicine and Public Health, vol. 38, pp. 19-26, 2007.

[23] M. Rohela, Y. A. Lim, I. Jamaiah et al., "Occurrence of Cryptosporidium oocysts in Wrinkled Hornbill and other birds in the Kuala Lumpur National Zoo.," The Southeast Asian journal of tropical medicine and public health., vol. 36, pp. 34-40, 2005.

[24] S. Uga, T. Oda, K. Kimura et al., "Detection of microorganisms in tap water in Indonesia and Thailand," Journal of Tropical Medicine and Hygiene, vol. 31, pp. 87-91, 2003.

[25] C. J. Chuah, N. Mukhaidin, S. H. Choy et al., "Prevalence of Cryptosporidium and Giardia in the water resources of the Kuang River catchment, Northern Thailand," Science of the Total Environment, vol. 562, pp. 701-713, 2016.

[26] C. Sutthikornchai, C. Jantanavivat, S. Thongrungkiat, T. Harnroongroj, and Y. Sukthana, "Protozoal contamination of water used in Thai frozen food industry.", The Southeast Asian journal of tropical medicine and public health., vol. 36, pp. 41-45, 2005.

[27] 2017, Kuching Water Board, Batu Kitang Water Works, https://www.kwb.gov.my/pages.php?mod=webpage\&amp;sub= page\&amp;id=58.

[28] P. Karanis and A. Kimura, "Evaluation of three flocculation methods for the purification of Cryptosporidium parvum oocysts from water samples," Letters in Applied Microbiology, vol. 34, no. 6, pp. 444-449, 2002.

[29] E. Kuczynska and D. R. Shelton, "Method for detection and enumeration of Cryptosporidium parvum oocysts in feces, manures, and soils," Applied and Environmental Microbiology, vol. 65, no. 7, pp. 2820-2826, 1999.

[30] D. P. Casemore, M. Armstrong, and R. L. Sands, "Laboratory diagnosis of cryptosporidiosis," Journal of Clinical Pathology, vol. 38, no. 12, pp. 1337-1341, 1985.

[31] R. Fayer, U. Morgan, and S. J. Upton, "Epidemiology of Cryptosporidium: Transmission, detection and identification," International Journal for Parasitology, vol. 30, no. 12-13, pp. 1305-1322, 2000.

[32] Y. R. Ortega and R. Sanchez, "Update on Cyclospora cayetanensis, a food-borne and waterborne parasite," Clinical Microbiology Reviews, vol. 23, no. 1, pp. 218-234, 2010.

[33] Centers of Disease Control and Prevention. (2017a). DPDx Laboratory Identification of Parasitic Diseases of Public Health Concern, https://www.cdc.gov/dpdx/az.html.

[34] L. J. Strausbaugh and B. L. Herwaldt, "Cyclospora cayetanensis: a review, focusing on the outbreaks of cyclosporiasis in the 1990s," in Clinical Infectious Diseases, pp. 1040-1057, 2000.

[35] T. Sun, C. F. Ilardi, D. Asnis et al., "Light and electron microscopic identification of cyclospora species in the small intestine: Evidence of the presence of asexual life cycle in human host," American Journal of Clinical Pathology, vol. 105, no. 2, pp. 216220, 1996.
[36] S. Tzipori and H. Ward, "Cryptosporidiosis: Biology, pathogenesis and disease," Microbes and Infection, vol. 4, no. 10, pp. 10471058, 2002.

[37] W. L. Current and N. C. Reese, "A comparison of endogenous development of three isolates of Cryptosporidium in suckling mice," Journal of Eukaryotic Microbiology, vol. 33, pp. 98-108, 1986.

[38] P. Karanis, I. Sotiriadou, V. Kartashev, C. Kourenti, N. Tsvetkova, and K. Stojanova, "Occurrence of Giardia and Cryptosporidium in water supplies of Russia and Bulgaria," Environmental Research, vol. 102, no. 3, pp. 260-271, 2006.

[39] Y. Tsushima, P. Karanis, T. Kamada et al., "Detection of Cryptosporidium parvum Oocysts in Environmental Water in Hokkaido, Japan," Journal of Veterinary Medical Science, vol. 63, no. 3, pp. 233-236, 2001.

[40] G. Vesey, J. S. Slade, M. Byrne, K. Shepherd, and C. R. Fricker, "A new method for the concentration of Cryptosporidium oocysts from water," Journal of Applied Bacteriology, vol. 75, no. 1, pp. 82-86, 1993.

[41] R. Aboytes, G. D. Di Giovanni, F. A. Abrams et al., "Detection of infectious cryptosporidium in filtered drinking water," Journal - American Water Works Association, vol. 96, no. 9, pp. 12-98, 2004.

[42] L. Nishi, M. L. Baesso, R. G. Santana, P. Fregadolli, D. L. M. Falavigna, and A. L. Falavigna-Guilherme, "Investigation of cryptosporidium spp. and giardia spp. in a public watertreatment system," Zoonoses and Public Health, vol. 56, no. 5, pp. 221-228, 2009.

[43] W. Q. Betancourt and J. B. Rose, "Drinking water treatment processes for removal of Cryptosporidium and Giardia," Veterinary Parasitology, vol. 126, no. 1-2, pp. 219-234, 2004.

[44] E. B. Hayes, T. D. Matte, T. R. O’Brien et al., "Large community outbreak of cryptosporidiosis due to contamination of a filtered public water supply," The New England Journal of Medicine, vol. 320, no. 21, pp. 1372-1376, 1989.

[45] I. Abubakar, S. H. Aliyu, C. Arumugam, N. K. Usman, and P. R. Hunter, "Treatment of cryptosporidiosis in immunocompromised individuals: Systematic review and meta-analysis," British Journal of Clinical Pharmacology, vol. 63, no. 4, pp. 387-393, 2007.

[46] R. Fayer, "Effect of high temperature on infectivity of Cryptosporidium parvum oocysts in water," Applied and Environmental Microbiology, vol. 60, no. 8, pp. 2732-2735, 1994.

[47] J. M. Colford Jr., T. J. Wade, S. K. Sandhu et al., "A randomized, controlled trial of in-home drinking water intervention to reduce gastrointestinal illness," American Journal of Epidemiology, vol. 161, no. 5, pp. 472-482, 2005.

[48] T. Matsui, J. Kajima, and T. Fujino, "Removal effect of the water purifier for home use against Cryptosporidium parvum oocysts," Journal of Veterinary Medical Science, vol. 66, no. 8, pp. 941-943, 2004.

[49] A. Nasir, M. Avais, M. S. Khan, and N. Ahmad, "Prevalence of cryptosporidium parvum Infection in Lahore (pakistan) and its association with diarrhea in dairy calves," International Journal of Agriculture and Biology, vol. 11, no. 2, pp. 221-224, 2009.

[50] T. K. Graczyk, B. M. Evans, C. J. Shiff, H. J. Karreman, and J. A. Patz, "Environmental and geographical factors contributing to watershed contamination with Cryptosporidium parvum oocysts," Environmental Research, vol. 82, no. 3, pp. 263-271, 2000 . 
[51] Centers of Disease Control and Prevention. (2017b). Healthy and Safe Swimming Week 2017 https://www.cdc.gov/features/ healthyswimming/index.html.

[52] T. Kistemann, T. Claßen, C. Koch et al., "Microbial load of drinking water reservoir tributaries during extreme rainfall and runoff," Applied and Environmental Microbiology, vol. 68, no. 5, pp. 2188-2197, 2002.

[53] M. Inoue, S. Uga, T. Oda, S. K. Rai, G. Vesey, and H. Hotta, "Changes of physical and biochemical properties of Cryptosporidium oocysts with various storage conditions," Water Research, vol. 40, no. 5, pp. 881-886, 2006.

[54] P. L. Young and S. J. Komisar, "Settling behavior of unpurified Cryptosporidium oocysts in laboratory settling columns," Environmental Science \& Technology, vol. 39, no. 8, pp. 2636-2644, 2005.

[55] X. Dai and J. Boll, "Settling velocity of Cryptosporidium parvum and Giardia lamblia," Water Research, vol. 40, no. 6, pp. 1321-1325, 2006.

[56] D. Sunderland, T. K. Graczyk, L. Tamang, and P. N. Breysse, "Impact of bathers on levels of Cryptosporidium parvum oocysts and Giardia lamblia cysts in recreational beach waters," Water Research, vol. 41, no. 15, pp. 3483-3489, 2007.

[57] T. K. Graczyk, D. Sunderland, L. Tamang, F. E. Lucy, and P. N. Breysse, "Bather density and levels of Cryptosporidium, Giardia, and pathogenic microsporidian spores in recreational bathing water," Parasitology Research, vol. 101, no. 6, pp. 17291731, 2007.

[58] D. Carmena, X. Aguinagalde, C. Zigorraga, J. C. FernándezCrespo, and J. A. Ocio, "Presence of Giardia cysts and Cryptosporidium oocysts in drinking water supplies in northern Spain," Journal of Applied Microbiology, vol. 102, no. 3, pp. 619629, 2007.

[59] K. Helmi, S. Skraber, J.-B. Burnet, L. Leblanc, L. Hoffmann, and H.-M. Cauchie, "Two-year monitoring of Cryptosporidium parvum and Giardia lamblia occurrence in a recreational and drinking water reservoir using standard microscopic and molecular biology techniques," Environmental Modeling \& Assessment, vol. 179, no. 1-4, pp. 163-175, 2011.

[60] T. Kumar, M. A. A. Majid, S. Onichandran et al., "Presence of cryptosporidium parvum and giardia lamblia in water samples from southeast asia: towards an integrated water detection system," Infectious Diseases of Poverty, vol. 5, no. 1, article no. 3, pp. 1-12, 2016. 

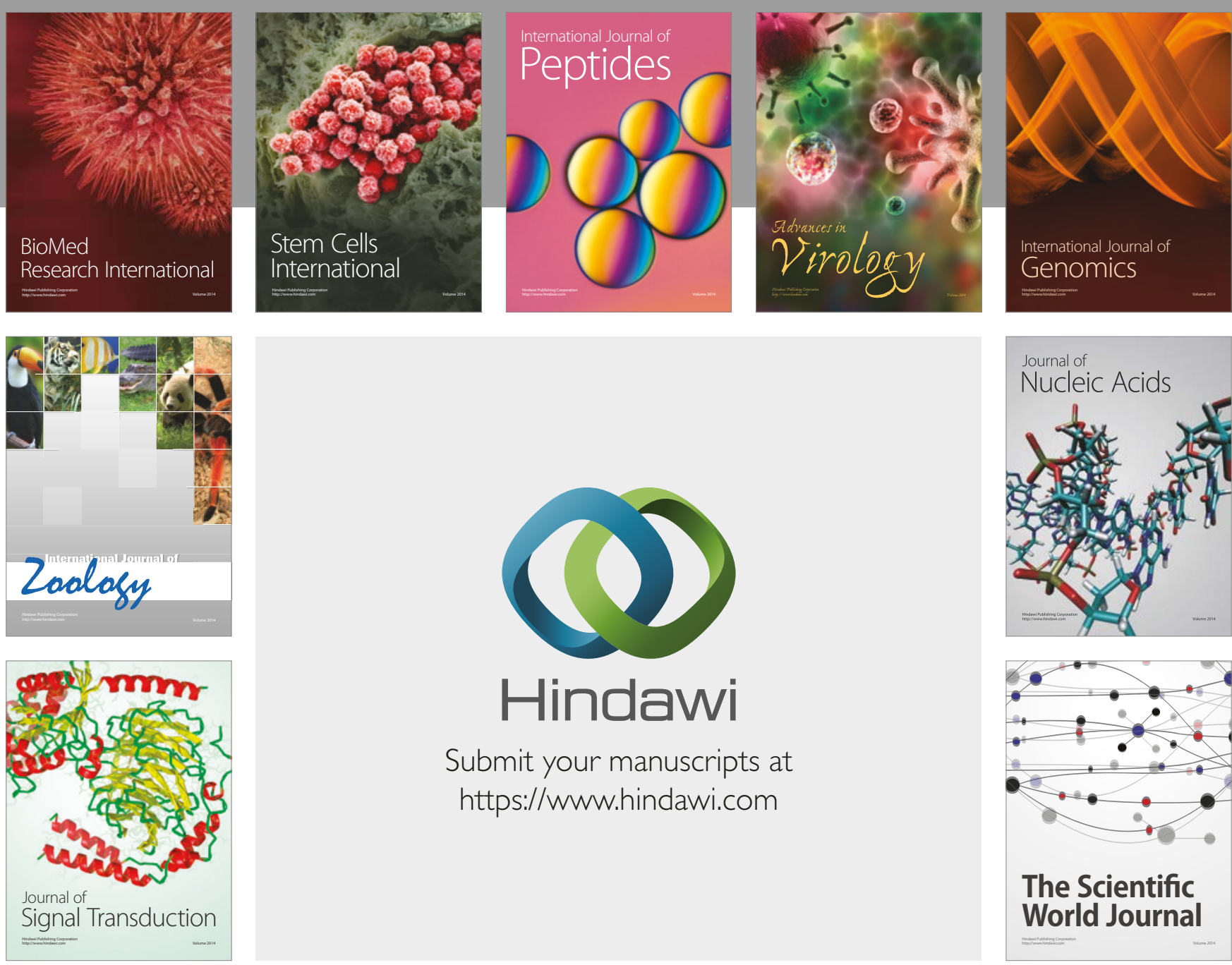

Submit your manuscripts at

https://www.hindawi.com
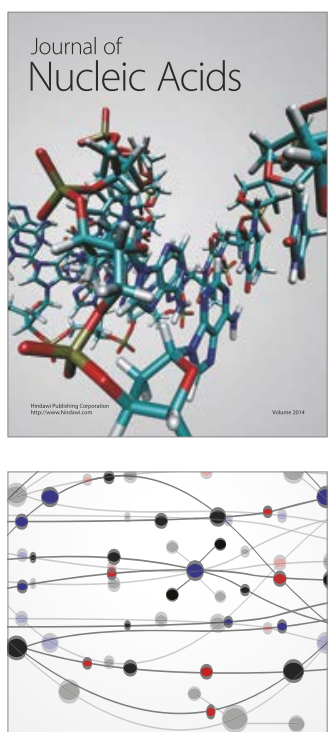

The Scientific World Journal

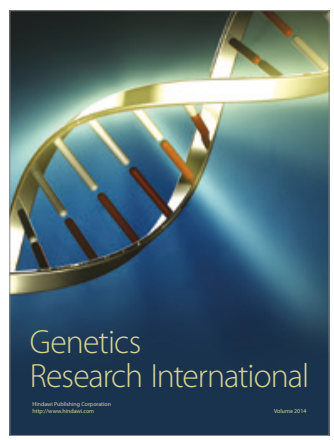

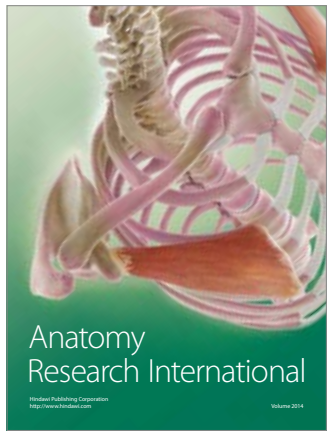

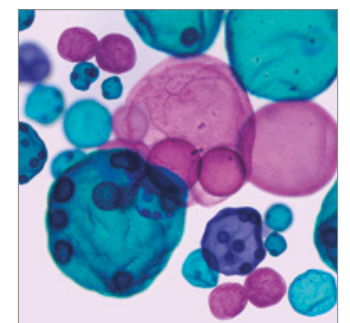

International Journal of Microbiology
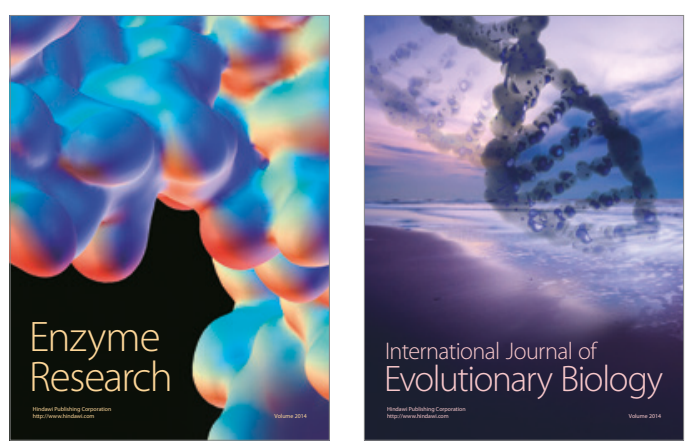
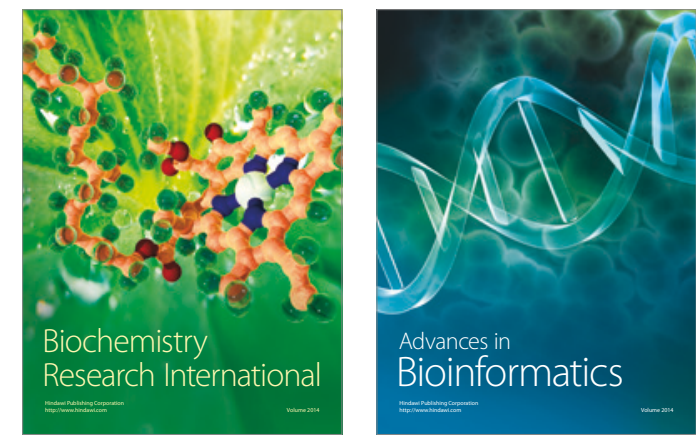

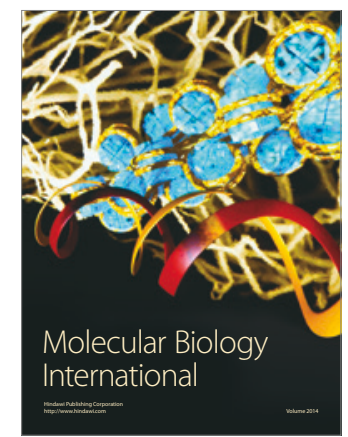

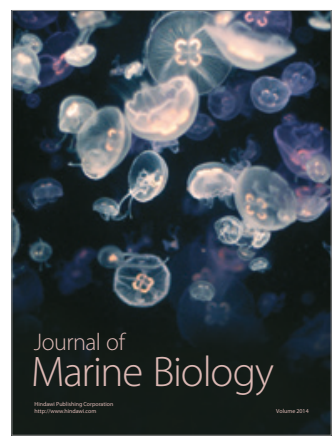

